\section{Un relato de experiencia para comprender a la Cultura Visual como estrategia metodológica}

M Rosario García-Huidobro rosarioghm@gmail.com

Universidad de Barcelona, España

García-Huidobro, Maria Rosario; (2012) "Un relato de experiencia para comprender a la Cultura Visual como estrategia metodológica", p. 288-293. In: Barbosa, Helena; Quental, Joana [Eds]. Proceedings of the 2nd International Conference of Art, Illustration and Visual Culture in Infant and Primary Education. São Paulo: Blucher, 2015. ISSN 2318-695X, ISBN: 978-989-98185-0-7 DOI 10.5151/edupro-aivcipe-55

Resumen

Para reflexionar entorno a los diversos enfoques, metodologías educativas, y desde éstos, proponer la utilización de recursos audiovisuales, como estímulos que desde la cultura visual, favorezcan caminos y formas de aprendizaje activo, me posiciono desde el lugar de mi práctica como docente en educación artística, para generar diálogos de interpretación y comprensión de subjetividades en los niños. Desde esta experiencia relato una vivencia personal, para analizar, interpretar y visualizar los desafíos, que desde la cultura visual, nos llevan a re-pensarnos y re-desearnos como profesores, y a nuestra implicación en los procesos de aprendizaje y estrategias de enseñanza hoy.

Palabras clave medio audiovisual, metodología, recurso educativo, cultura visual.

To reflect on the various approaches, educational methodologies, and from these, propose the use of audiovisual resources, as a stimulus that from visual culture, favors roads and forms of active learning, I positioned from the place of my practice as a teacher in Arts education, to generate dialogs of interpretation and understanding of subjectivities in children. From this experience, I narrate a personal story, to analyze, interpret and visualize the challenges, that since the visual culture, lead us to re-thinking about and re-desire as teachers, and our involvement in the processes of learning and teaching strategies today.

Keywords

audiovisual media, methodology, educational resource, visual culture.

\section{Introducción}

Para reflexionar entorno a los diversos enfoques y metodologías educativas, y su relación con la cultura visual hoy, es necesario iniciar este escrito posicionándome desde el lugar de mi práctica como docente en educación artística en mi país. En este sentido, no estoy aquí para revelar una verdad, ni mucho menos para denunciar carencias o limitaciones. Como docente novel, quisiera hablar desde las dudas que supone adentrarse en el mundo de la educación, y a través de mi propia práctica y reciente experiencia docente, compartir el relato de un caso. Narrarles una vivencia personal, desde el contexto de trabajo en aula, la cual hoy, al mirarla en perspectiva, me permite reflexionar respecto a los aportes que los recursos audiovisuales, como estrategias metodológicas que desde la cultura visual, pueden fomentar espacios de aprendizaje activo. En este documento se comprende y presenta a la cultura visual, desde la importancia que autores como Hernández (2007) y Mirzoeff (2003), señalan en las formas de comprenderse a uno mismo, desde el imaginario visual que nos rodea. En este sentido, a través de esta comprensión se plantea un debate respecto al significado de una metodología activa y el aporte que los medios audiovisuales pueden adoptar como recurso educativos para favorecer, tanto la comprensión de la cultura visual en los niños, como de otros contenidos, desde medios propios 
2nd International Conference

Art, Illustration and Visual Culture

in Infant and Primary Education $2^{\circ}$ Congreso Internacional

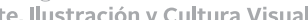
en Educación Infantil y Primaria
Congresso Internacional

de Arte, Ilustração e Cultura Visual

na Educação Infantil e Primária

de este fenómeno actual. Para concluir, se entregan algunas características del tipo de recurso que pueda responder al cómo utilizar la cultura visual, o lo que ésta nos brinda como estrategia educativa que estimule y promueva aprendizajes activos y colaborativos.

\section{Un relato de experiencia}

Soy profesora de artes visuales en Chile. Me especialicé en la formación artística de jóvenes adolescentes de secundaria, y en mi lugar de trabajo en el colegio, Nuestra Señora de Loreto, desarrollaba no sólo cursos prácticos y experimentales sobre artes visuales, sino que también sobre teoría, estética e historia del arte y orientaba la elaboración de proyectos artísticos. Las metodologías que adoptaba, desde el trabajo práctico con los diversos cursos, eran principalmente participativas, e intentaba que los jóvenes aprendieran desde su experimentación y experiencia personal. Apoyaba mis clases con presentaciones y utilizaba gran variedad de recursos audiovisuales, para no sólo intentar motivarlos desde lo visual, sino que también compartir con ellos todo lo que el arte pone a nuestra disposición como referente cultural.

Sin embargo, algo sucedió en mi rol docente cuando la institución me invitó a generar talleres artísticos para niños y niñas de primaria, entre 6 y 8 años. A pesar de la ilusión que esta invitación me suponía, me sentía algo intranquila, ya que nunca me había enfrentado a niños de aquella edad. Sin tomar consciencia de lo que ello me supondría después, cree el taller, "Creando autorretratos con mis objetos". Éste proponía, invitar a los niños a explorarse y conocerse, mediante la creación de sus autorretratos, desde su experiencia de subjetividad y su relación con los objetos, sobre todo aquellos con los que mayoritariamente se identificaban (sus juguetes, calcomanías, libros, fotos, diversos objetos personales, entre otros.), para a partir de éstos interpretarse y representarse. A su vez, intenté planificar para el taller una metodología de enseñanza que fuera acorde no sólo a la edad, sus intereses, deseos y expectativas, sino que también al tipo de taller al que los invitaba a participar. Ésta suponía en primera instancia, al igual como lo desarrollaba con los chicos de secundaria, realizar un trabajo teórico, invitarlos a conocer el significado del autorretrato, y de a poco ir analizando de qué manera se identificaba e interpretaba cada uno, para luego comenzar el trabajo creativo con sus objetos. Jamás pensé que esta experiencia desconocida limitaría mi rol docente.

El problema que ello me suscitó, fue el momento cuando me enfrente a niños con los que habitualmente no acostumbraba a relacionarme. El conflicto personal se hallaba en el no saber de qué manera enfocar u orientar mi rol docente, para trabajar con niños de primaria. Creí que aquella metodología, que desde los libros y las teorías educativas que tenía planificada me ayudaría. Sin embargo en aquellos momentos caí en cuenta que nada de eso me servía. Entonces me pregunté, ¿hasta qué punto una metodología educativa limita o condiciona un rol docente?, ¿Qué significa adoptar una metodología?

A través de esta experiencia logré comprender que para entrar en dinámica con estos niños debía re-pensar mi posición como profesora, para así comprender desde dónde plantearía una nueva metodología. Sin lugar a dudas, desarrollar en ellos una verdadera motivación y consciencia de sí mismos, para trabajar el tema del autorretrato, desde su subjetividad y capacidad de expresión artística, no podía utilizar la misma metodología o estrategias que empleaba con chicos mayores, más aún, si tomaba en cuenta no sólo su edad y contexto, sino que también, sus deseos por aprender a través del arte, sus conocimientos previos y sobre todo, si valoraba que el taller que propuse, proponía la utilización de sus objetos cotidianos, como materiales que simbolizaban un encuentro de subjetividades.

Desde este re-pensar mi posición, me pregunté por mi rol como profesora y desde dónde debía situarme para proponer el taller, ya que éste, por más que tratara un tema complejo y profundo a mis ojos, para los niños debía revelarse como una experiencia para aprender y conocer de sí mismos y los demás, desde su contexto visual, en un espacio entretenido, lúdico y de creación. Sin lugar a dudas, el problema no eran los niños, sino que mi manera de concebir e interpretar las metodologías o la manera en que los estaba invitando a participar. Situada en esta experiencia, comprendí que mi desafío era buscar una metodología que generara un espacio y una situación apropiada para lograr los objetivos de dicho taller, por ende, las estrategias didácticas de apoyo, se convertían en herramientas de suma importancia en aquella instancia de aprendizaje. 
$2^{\text {nd }}$ International Conference Art, Illustration and Visual Culture in Infant and Primary Education $2^{\circ}$ Congreso Internaciona

Arte, Ilustración y Cultura Visual en Educación Infantil y Primaria
Gresso Internacional

de Arte, llustração e Cultura Visual

na Educação Infantil e Primária
Figuras 1, 2, 3, 4 y 5 . Hanoch Piven Strauss-Group Piven Campaign (2008) Las cinco imágenes son parte de un video del artista, y señalan la secuencia donde crea una caricatura a partir de elementos comestibles.
Desde estas inquietudes comencé la búsqueda de ideas y estrategias, que desde sus intereses visuales y contexto, me ayudara a orientar mi práctica en el taller. Así fue como decidí explorar, a través de internet, diversos artistas y videos, que me ayudaran a generar mayor motivación, y una dinámica lúdica, mágica y entretenida, que nos permitiera mirarnos y comprendernos a la hora de iniciar el taller. Desde esta investigación, descubrí una serie de videos e ilustraciones del artista, Hanoch Piven ', los que al ser presentado a los niños, marcaron un giro significativo del taller. Éstos eran una serie de videos de diferentes trabajos personales, realizados para campañas publicitarias para la televisión Israelita y Catalana (España). Los videos, de corta duración, señalaban de manera lúdica y entretenida como crear rostros a partir de diferentes elementos, como por ejemplo crear un cuerpo con elementos comestibles, como dulces, brownies, plátano, yogurt, etc. (Figuras 1, 2, 3, 4 y 5) u objetos cotidianos (herramientas de construcción, legos, globos, lápices, etc.)
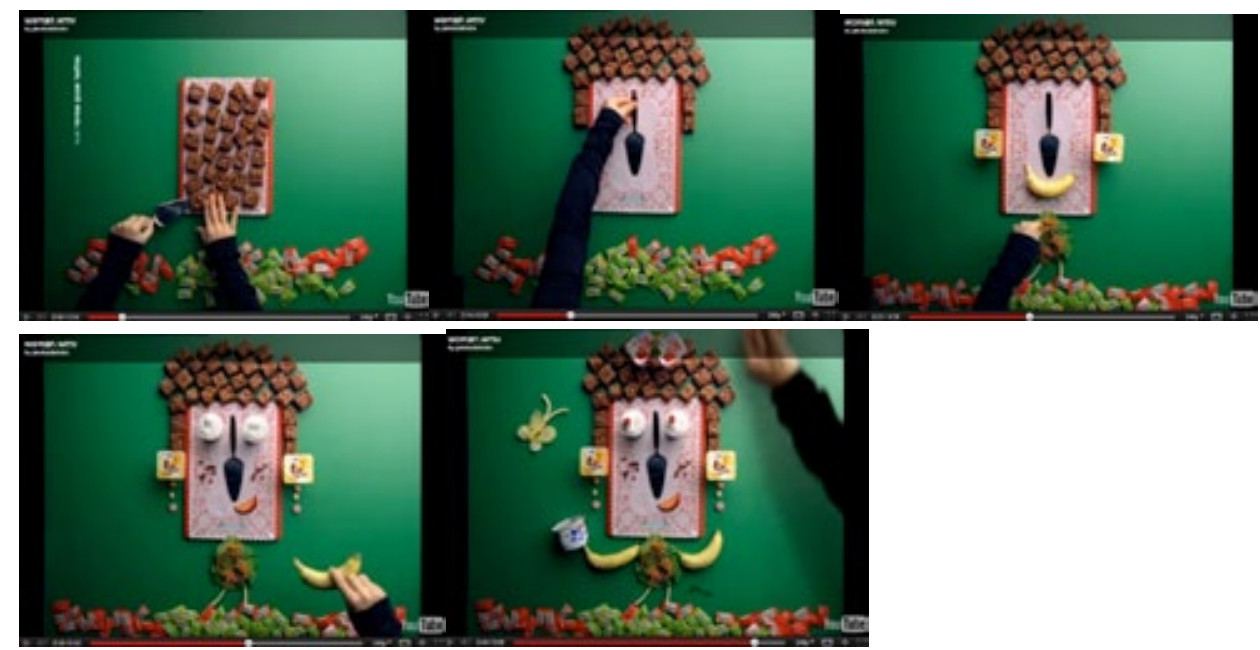

Ver estos videos me trasladaron rápidamente a re-pensar mi posición como profesora de primaria y la manera en que estaba invitando a los niños a participar en el taller. Desde aquí comprendí lo que significaría generar un espacio lúdico y de miradas, si utilizara estos videos como estrategia educativa.Así, cada día del taller iniciábamos la sesión con la proyección de un video distinto o comentando una obra del artista. Interpretábamos de manera conjunta las representaciones y compartíamos de qué manera cada uno se podría identificar con aquellas formas, colores y objetos. En ellos surgían risas, se sorprendían y rápidamente eran capaces de imaginar diversos elementos con los cuales identificarse a ellos mismos, para hablar de sí.

Si bien soy consciente que los recursos visuales y/o audiovisuales, no deben en ningún caso ser el sustituto del profesor, en esta situación, éstos eran una herramienta para generar en el taller un espacio y ambiente más acogedor y creativo. Así, los niños se sentían convidados a interpretarse, no sólo desde las historias que yo y los recursos empleados narraban, sino porque los videos se transformaban en estímulos que generaban, tanto un ambiente abierto, flexible y propicio para el trabajo creativo, como una manera diferente que los invitaba a relatarse a ellos mismos, para a partir de estos ejemplos comprender las diversas formas de interpretación personal, que permitiera abordar el tema del autorretrato y la importancia de los diversos objetos que traían consigo para representar su subjetividad.

Mediante esta nueva forma de interacción se logró romper, no sólo el ambiente rígido que desde mi posición, como profesora disciplinada de secundaria traía, sino que a su vez logré comprenderme a mí, en la dualidad de lo que significa trabajar temas de subjetividad con jóvenes de secundaria y a su vez con niños de primaria. El apoyo de estímulos visuales lúdicos, 
2nd International Conference Art, Illustration and Visual Culture in Infant and Primary Education $2^{\circ}$ Congreso Internaciona

Arte, Ilustración y Cultura Visual en Educación Infantil y Primaria
Congresso Internacional

de Arte, llustracão e Cultura Visual

na Educação Infantil e Primária

\subsection{Una experiencia de cambio para comprender a la Cultura Visual como estrategia metodológica}

me permitieron generar un espacio de aprendizaje de diálogo, para compartir las miradas de los niños a sí mismos y sus subjetividades.

Han pasado dos años desde el relato de esta experiencia. Actualmente pienso en ella con perspectiva y logro identificar diversos elementos significativos, que en su momento no logré comprender y que hoy resuenan, para reflexionar respecto a los enfoques metodológicos y el lugar que la cultura visual ocupa en ellos y en nuestra práctica pedagógica diaria.

En primer lugar, desde el caso compartido, creo significativo reflexionar sobre el significado de nuestras posiciones como docentes, en las estrategias metodológicas que adoptamos en el proceso de enseñanza y a su vez, valorar los aportes que la cultura visual generan como medios y estímulos, en las dinámicas educativas. Bien sabemos que, respecto a los retos sobre educación hoy, es prioritario fomentar una metodología de tipo activa, más aun si pensamos en generar un aprendizaje significativo en niños y niñas de primaria. En este sentido, tal como lo descubrí yo en mi experiencia, es fundamental ir más allá de las clases magistrales, dónde el profesor transmite verticalmente sus conocimientos a los alumnos y éstos, bajo un rol pasivo, deben acatarlos o asimilarlos. Hoy se plantea, desde un enfoque socioconstruccionista, entregar a los estudiantes un papel protagonista y activo, en el proceso de adquisición del conocimiento. Leerse, interpretarse y comprenderse, son algunas de las características que permiten generar un aprendizaje significativo.

Este llamado resuena en mis prácticas artísticas, desde la manera en cómo me posiciono, y me traslada a preguntarme, ¿qué deseo enseñar y cómo? En este sentido el posicionamiento docente se vuelve fundamental y se encuentra ligado a la metodología que utilizará, porque para re-pensar, cómo invitar a los niños a participar en un espacio y lugar de trabajo artístico, que les posibilite interpretarse y narrarse desde su subjetividad, caigo en la cuenta que debo pensar como ellos, y hasta cierto límite, ser uno más de ellos en las dinámicas educativas que ocurren en el aula.

Adentrados a este punto, destaco en primera instancia, la importancia que significa desde el trabajo artístico y creativo, no sólo con niños de primaria sino que también con jóvenes de secundaria, cuestionar nuestra posición como docentes para alcanzar una enseñanza activa. El cambio que esto supone nos invita a re-pensar nuestros enfoque metodológico y cuál es nuestro rol docente en éste. No dejo de pensar que un trabajo colaborativo, conlleva un cambio en la disposición vertical que experimentamos muchas veces como profesores con el alumno, así como también generar mayor relación entre los estudiantes como estrategia para una construcción de aprendizajes compartidos. Desde aquí me pregunto, ¿Que significaría, desde este cambio de posición del profesor, adoptar nuevas estrategias metodológicas?

Sin duda alguna, adoptar esta nueva posición y hurgar nuevas estrategias metodológicas me traslada nuevamente, a pensar en los niños, sus intereses, deseos, sensibilidad con la qué observan y admiran el mundo y la realidad, para a partir de ello buscar estrategias de enseñanza. Desde este desafío, no debemos olvidar que pertenecemos a una sociedad globalizada, con niños y jóvenes que desde pequeños poseen una relación cotidiana con la cultura visual y los productos mediáticos, entendiendo a éstos últimos como todos los artefactos e imágenes que nos rodean y ayudan a crear nuestro imaginario visual. En este sentido, reflexionar sobre la cultura visual que rodea a los niños, no implica únicamente pensar en los referentes visuales que los rodea desde la televisión, películas, música, libros, juegos, diseño, publicidad, etc., sino que valorar y re-pensar que, ellos son quienes hacen uso constante del potencial que ofrece la cultura visual, lo que explica que,

"El imaginario de los jóvenes se compone en buena medida por recursos propios de la cultura de masas, como personajes televisivos, estrellas musicales o ídolos deportivos, que conviven con las fotografías familiares, las imágenes de la infancia o los recuerdos de los amigos" (Aguirre, 2011,4)

Así bien, si los niños y jóvenes nacen y conviven en contextos donde la tecnología y la gran diversidad de información visual es parte de su ideario cotidiano, entonces la cultura visual se 
vuelve altamente atractiva, tanto para su desarrollo de aprendizaje artístico como búsqueda de identidad. En este contexto, lo anterior nos orienta a enfocarnos en la búsqueda de un tipo de metodología, que desde sus estrategias, promueva un aprendizaje activo, desde lo que significa valorar su relación con la cultura visual. Para esto creo relevante incluir, como parte de un nuevo posicionamiento docente, que comprende la enseñanza desde los intereses de los niños, es decir, desde lo que significa la cultura visual en sus vidas y formación de subjetividad, una nueva postura frente a un enfoque metodológico que promueve un aprendizaje desde la comprensión de la cultura visual.

Ahora bien, si la finalidad, "de la cultura visual en la Educación de las artes visuales es «llevar a cabo un cuestionamiento y análisis crítico de las experiencias culturales y los textos de la vida diaria»" (Hernández, 2007, 61), creo significativo otorgarle a ésta, un papel fundamental en los medios o recursos metodológicos, que como docentes utilizamos para estimular, orientar o complementar nuestra enseñanza a los niños. Desde esta invitación, se vuelve favorable para la enseñanza de artes visuales, incluir estrategias metodológicas, como recursos que desde los medios audiovisuales no sólo señalen imágenes u objetos de la cultura visual. Si "la importancia primordial de la cultura visual es mediar en el proceso del cómo miramos y cómo nos miramos" (Hernández, 2010, 64), entonces como docentes no sólo es relevante enseñar a relacionarse con ella, sino que a partir de ésta, generar espacios que los inviten a buscar aquellas relaciones con ellos mismos.

"La cuestión no son sólo los objetos, sino cómo estos se abordan, la indagación que posibilitan y el espacio de interacción e intercambio que nos brindan en esa encrucijada entre la mirada de la realidad que construyen y la mirada cultural que los visualizadores proyectan". (Hernández, 2010: 11)

En este sentido, sería comprender que utilizar recursos multimedia como estrategia metodológica, desde los intereses visuales de los niños, se revela como una invitación hacia ellos, a aprender desde aquello que los motiva, sorprende y que además permite leer e interpretar diversas lecturas, incluso la de ellos mismos. A modo de ejemplo, en la experiencia de práctica docente anteriormente relatada, las narrativas visuales de los videos utilizados, permitieron crear situaciones en el aula y experiencias en los niños que los invitaba a establecer relaciones entre, las imágenes que se formaban con los diversos objetos y sus experiencias de mirada y maneras de comprenderse a ellos mismos, a la hora de autorretratarse con sus objetos.

Por otro lado resulta evidente, que la solución no está simplemente en el hecho de utilizar recursos audiovisuales como estrategia metodológica, sin un criterio que favorezca las relaciones de enseñanza, y fomente los aportes que entrega la cultura visual como medio y estímulo de aprendizaje. Recordemos que el objetivo de estos medios, son por un lado actuar como recursos que favorecen el proceso de aprendizaje o la enseñanza de un tipo de contenido, pero a su vez, juegan la dualidad de ser en sí mismos, un contenido propio de la cultura visual. Es decir que, desde el mundo de la cultura visual, un recurso audiovisual (película, canción, video, imagen, artefacto, etc.), puede aportar por un lado, como medio e incentivo de enseñanza (al ser un apoyo y complemento en las prácticas del profesor) y a su vez contiene en sí mismo, aquello que como profesores debemos mostrar y transmitir sobre los significados e importancia de la cultura visual, para propiciar espacios y miradas de encuentro e interpretación personal. En este sentido, el profesor debe actuar como un agente que media desde un rol activo, y propone al material como un elemento que invita a la reflexividad, al encuentro y diálogo entre la cultura visual y nosotros mismos.

\section{Conclusión}

Finalmente, reflexionar respecto a las posibilidades que la cultura visual nos brinda para generar recursos o estrategias que complementen nuestra metodología en el aula, son múltiples y complejas. En este sentido, establecer criterios propicios para buscar dicho material no es tarea sencilla. Desde la cultura visual que nos rodea a nosotros y a los niños, existe infinito material que, desde sus diversas particularidades y formas de aplicación, pueden actuar como grandes aportes para mediar conocimientos y de manera paralela, ser un conocimiento en sí mismo.

Desde este lugar y a modo de conclusión, cierro este apartado planteando diversas características que podrían orientar la búsqueda de medios audiovisuales como recursos y estrategias de enseñanza, que desde la cultura visual, podrían propiciar caminos favorables 
hacia una metodología de aprendizaje activa en el aula. Primero, favorecer recursos que posean elementos narrativos. Buscar medios que, desde su interpretación simbólica, sean contadores de historias y promuevan desde la comunicación, una implicación de los jóvenes y niños, como un llamado a relatar sus historias y preguntarse de qué manera se identifica cada uno. Por otro lado, es importante buscar recursos abiertos que permitan a los diversos jóvenes y niños encontrarse e identificarse con o a través de éstos. A su vez que permita diferentes lecturas y formas de comprender la realidad. También es significativo indagar en tipo de recursos interactivos, es decir que sean colaborativos y que inciten a compartir las diferentes miradas y construir sus significados, desde el diálogo y lo que cada uno se siente llamado a aportar y contar. Así, buscar medios que se adapten a los intereses visuales que rodean a los niños y jóvenes, desde su contexto y edad. Por último, utilizar recursos que promuevan aspectos lúdicos, es decir, que desde sus aspectos formales o desde el contenido que se transmite, se fomente la sorpresa y la expresión, como un llamado a descubrirse y reconocerse, desde el asombro y la conmoción.

\section{Referencias bibliográficas}

Aguirre, I. (2011) El Mercado Mediático y la Configuración de los Criterios y Experiencias Estéticas de los Adolescentes. Granada: Dykinson.

Hernández, F. (2010) Educación y Cultura Visual. Barcelona: Octaedro.

Hernández, F. (2007): Espigadoras de la Cultura Visual. Barcelona: Octaedro.

Hernández, F. (2011): Investigación Narrativa y Cambio Social. Barcelona: Octaedro.

Mirzoeff, N. (2003) Una Introducción a la Cultura Visual. Barcelona: Paidos.

Ranciére, J. El Espectador Emancipado. Paris: Ellago.

Piven, H. http://www.pivenworld.com (En línea) http://www.pivenworld.com/strauss-campaign-2/tvadvertising-by-hanoch-piven (Consulta: 29-03-2012) 